\title{
GERANIUM'S RESPONSE TO COMPOST BASED SUBSTRATES
}

\author{
R. López, C. Durán, J.M. Murillo, F. Cabrera \\ Instituto de Recursos Naturales y Agrobiología de Sevilla \\ CSIC
}

Apartado 1052

41080 Sevilla

Spain

Additional index words: Pelargonium zonale, municipal solid waste, pine bark, cotton gin trash

\begin{abstract}
$\underline{\text { Abstract }}$
The effects of compost based substrates on growth and nutrition of geranium (Pelargonium zonale cv Lucky Break F2) were investigated. Substrates of manure compost, cotton gin trash compost, municipal solid waste compost and pine bark utilized as potting media for domestic use, produced an underdevelopment of geranium plants with respect to the control. This behaviour is related to the inferior physical properties of the compost-based potting media, nitrogen immobilization due to the high $\mathrm{C} / \mathrm{N}$ ratio of pine bark, and probably lack of available phosphorus originated by high calcium and high $\mathrm{pH}$ of the compost-based media. Nitrogen fertilization and a longer period of cultivation diminished the differences between plants grown in the control and in compost-based media. Plants grown in compost mixtures which were rich in $\mathrm{K}$ showed $\mathrm{K}$ and $\mathrm{Ca}$ leaf contents closer to the optimum range than did control plants.
\end{abstract}

\section{$\underline{\text { 1. Introduction }}$}

In southern Spain, various residues, such as grape marc, cotton gin trash, manures, cork, bark, sawdust, coconut fibre dust and sewage sludge, are being used as components of substrates for domestic use. These products are generally utilized after composting and in some cases after long periods of maturation. Many of the substrates are sold without enough knowledge of their properties and behaviour, and so the appropriate plants for each substrate and the additional needs for fertilizers or irrigation are unknown. These organic products are utilized as pure potting media, mixed with peat, sand or soil, and as organic amendment of soil.

This paper describes the results (mainly growth and nutritional parameters) obtained when geranium (Pelargonium zonale cv Lucky Break F2) was grown in compost-based substrates. The geranium was selected because it is a common house and garden plant in southern Spain. 
The experiment was carried out under reduced irrigation because water scarcity is common in the region, sometimes even to the extent that it is strictly forbidden to water ornamental plants. No fertilizers were added during the first part of the experiment because one aim of the work was to determine the potential capacity of the substrates to give nutrients to the plants, and also because this is common practice in the region.

\section{Materials and Methods}

\subsection{Potting media}

Potting media were as follows: (1) Control (C), a good quality commercial substrate made up of peat supplemented with mineral fertilizer. (2) Naturplant (M), a commercial substrate from Fertilizantes Orgánicos Melguizo S.L., Los Palacios, Sevilla, Spain, made up of composted manure and composted cotton gin trash. Manure and cotton gin trash (fibre, seeds and burr of cotton) were separately composted in windrows for several months and left to mature for one year. Composts based on cotton gin trash have been successfully used as organic fertilizer for cotton and corn (Madejón et al. 1995, 1996). (3) M2P1, a mixture of M and white peat (P) (2:1 vol/vol). (4) M1SW1P1, a mixture of M, composted municipal solid waste (SW) and $P$ (1:1:1 in volume). Solid waste was collected from the composting facilities in Villarrasa, Huelva, Spain. After screening to $<6.0 \mathrm{~cm}$, this municipal solid waste was composted for $49 \mathrm{~d}$ in outdoor windrows turned six times, followed by a $60 \mathrm{~d}$ period of maturation. Final screening reduced the particle size to $<10 \mathrm{~mm}$ and the compost was passed through a light/heavy separating fluidized deck to remove dense particles such as glass and ceramics. (5) M1B1, a mixture of $M$ and pine bark (B) $(1: 1 \mathrm{vol} / \mathrm{vol})$. Pine bark was aged for two years but not composted under controlled conditions. Before mixing, $B$ was ground to $<10 \mathrm{~mm}$.

\subsection{Growth conditions}

The experiment was carried out in a greenhouse. Seeds of geranium were germinated in peat. After 2 weeks homogeneous plants were planted in 11 plastic pots filled with the potting media described above. Eight plants per potting media (40 pots) were randomly distributed in the greenhouse. Pots were irrigated with tap water/Electrical Conductivity (EC $0.6 \mathrm{dS} \mathrm{m} \mathrm{m}^{1}$, SAR 1.2). Watering was done once/twice per week according to greenhouse and plant conditions to allow appreciable desiccation of the potting media before each irrigation. All the pots received the same volume of water (slightly in excess to permit leaching and avoid salinization).

Plant height was measured at 45 and $100 \mathrm{~d}$ after planting. At day 45 four plants per treatment were taken and fresh and dry weight were determined. After day 45 the remaining plants were irrigated with a $150 \mathrm{mgN} \mathrm{I}^{-1}$ (as $\mathrm{NH}_{4} \mathrm{NO}_{3}$ ) solution. At day 100 these plants were weighed, dried and analyzed. 


\subsection{Analytical methods}

Physical characteristics of potting media were determined following Inbar et al. (1993) and Chen et al. (1988). EC and pH were determined in 1:6 (vol/vol) extract of fresh samples. Cation exchange capacity (CEC) and exchangeable bases were measured following Gillman (1979) as modified by Ansorena (1994). "Available" micronutrients were extracted with DTPA using the Lindsay \& Norvell (1978) procedure. Nitrogen was measured after Kjeldahl digestion by an automatic photometric technique in the case of leaf samples and by steam distillation in the case of potting media. Other nutrients in leaf and potting media samples were determined by atomic absorption after dry ashing and uptake in $\mathrm{HCl}$. The quality of analytical results ("total" concentration of elements in potting media and nutrient leaf concentration) was checked by running control samples corresponding to the programs MARSEP and IPE of Wageningen Evaluating Programmes for Analytical Laboratories (WEPAL).

Data were analyzed by ANOVA and the differences between treatments were compared using Tukey's test. A significance level of $\mathrm{p}<0.05$ was considered throughout the study.

\section{$\underline{\text { 3. Results and discussion }}$}

The control potting medium, C, showed better physical properties (Table 1) than the M-based media. Mixtures M1SW1P1 and M1B1 had container capacity and air space different to those of an ideal substrate (de Boodt \& Verdonck, 1972). Chemical properties of the potting media are shown in Table 2.

Plant development at 45 days is shown in Figure 1, and the leaf contents of NPK at this date are shown in Table 3. Due to the small number and size of plants at this stage it was decided to take composite samples for each treatment which were analyzed in duplicate. For this reason statistical analysis could not be made.

Plants grown in $\mathrm{C}$ showed the greatest weight, and were significantly different to those of all other treatments, probably because of the better physical properties (Table 1) and lower $\mathrm{pH}$ of $\mathrm{C}$ (Table 2). Plants grown in $\mathrm{C}$ showed lower $\mathrm{N}$ content than those of treatments M, M2P1 and M1SW1P1 (Table 3), possibly due to the dilution effect produced by their higher biomass.

Plants grown in M1B1 were the smallest, although their weight was not significantly different to that of those grown in $\mathrm{M}$ and M1SW1P1 mixtures. Plants grown in M1B1 also had the lowest $\mathrm{N}$ content (Table 3), which was equal to the deficiency limit given by Bunt (1983) and Ansorena (1994). M1B1 C/N ratio was higher than that of M, M2P1 and M1SW1P1 (Table 2) due to the high $\mathrm{C} / \mathrm{N}$ ratio of 
pine bark $(\mathrm{C} / \mathrm{N} 156)$. Thus, probably the high $\mathrm{C} / \mathrm{N}$ ratio of pine bark provoked $\mathrm{N}-$ immobilization in the M1B1 medium.

Plants grown in M and M1SW1P1 media also showed a low development (Figure 1). The phosphorus content of M and M1SW1P1 plants (Table 3) was below the deficiency limit (P 0.24\%) (Bunt 1983, Ansorena 1994). Phosphorus availability in these potting media could have been decreased by their high $\mathrm{pH}$ and total $\mathrm{Ca}$ content (Table 2).

Plants grown in M2P1 had a development intermediate between those of plants grown in $\mathrm{C}$ and the other $\mathrm{M}$-based media (Figure 1). These plants also had a phosphorus content intermediate between plants grown in C and in M or M1SW1P1 (Table 3), which was over the deficiency limit but below the normal range of phosphorus in geranium plants (P 0.4-0.67\%) (Bunt, 1983, Ansorena, 1994). Peat in M2P1 medium reduced the $\mathrm{pH}$ of $\mathrm{M}$ (Table 2) and probably increased phosphorus availability to plants.

Plant fresh and dry weights correlated linearly with height $\left(\mathrm{r}^{2} 0.80\right)$, so the remarks for fresh weight could be extended to the other growth parameters. Growth parameters and nutrients in plants at day 100 are shown in Figure 2 and Table 3 respectively. After the period of $\mathrm{N}$-fertilization (days 45 to 100), the behaviour of plants in the potting media was different to that observed at 45 days.

Plants grown in M1SW1P1 were the smallest, their fresh weight being statistically different to those in C, M2P1 and M1B1 media (Figure 2). Leaf nutrient contents of plants grown in M1SW1P1 did not show differences that could explain their lower development (Table 3). Leaf $\mathrm{Zn}$ content of M1SW1P1 plants was the highest, in accord with the highest Zn-DTPA content found (in M1SW1P1) (Table 2), but it was not statistically different to the other treatments. Heavy metal contents in the municipal solid waste compost (data not shown), though more elevated than in the other products, were well below accepted limits for ornamental plants (Verdonck et al., 1987). Nevertheless, M1SW1P1 showed evident volume contraction, making the watering of this medium difficult.

From days 45 to 100 , plants in M1B1 increased their weight and height to a greater extent than those in the other treatments (Figure 2), being similar to control plants and having a similar $\mathrm{N}$-content (Table 3 ). The positive response of these plants to $\mathrm{N}$ fertilization proves that $\mathrm{N}$-deficiency was the cause of their low development at 45 days.

Plants in M and M2P1 media showed at 100 days an intermediate size between C and M1B1 plants (though not statistically different). Although plants from all media showed 'phosphorus leaf content below the normal range, there were no statistically significant differences between the 5 potting media. It seems that $\mathrm{N}$-fertilization corrected the observed phosphorus deficiency at day 45 . 
At both day 100 (Table 3) and day 45 (data not presented) plants grown in Mbased media showed higher $\mathrm{K}$ and lower $\mathrm{Ca}$ and $\mathrm{Na}$ contents than plants grown in $\mathrm{C}$, in accord with higher total- and exchangeable- $\mathrm{K}$ in M-based media (Table 2). The $\mathrm{K}-$ $\mathrm{Ca}$ antagonism led to more adequate $\mathrm{K}$ and $\mathrm{Ca}$ leaf contents in plants grown in $\mathrm{M}$ based media, which in the case of the control plants were outside normal ranges of $\mathrm{K}$ 2.5-4.5\%, Ca 0.81-1.2\% (Bunt, 1983, Ansorena, 1994).

\section{Conclusions}

Substrates of manure compost, cotton gin trash compost, municipal solid waste compost and pine bark utilized as potting media for domestic use, produced an underdevelopment of geranium plants with respect to the control. This behaviour is related to the inferior physical properties of the compost-based potting media, nitrogen immobilization due to the high $\mathrm{C} / \mathrm{N}$ ratio of pine bark, and probably lack of available phosphorus originated by high calcium and high $\mathrm{pH}$ of the compost-based media.

Nitrogen fertilization and a longer period of cultivation diminished the differences between plants grown in the control and in compost-based media. Plants grown in compost mixtures which were rich in $\mathrm{K}$ showed $\mathrm{K}$ and $\mathrm{Ca}$ leaf contents closer to the optimum range than did control plants. Sodium leaf content of plants grown in compost-based potting media was lower than that in the control plants, which could allow irrigation with poor quality water, a common situation in arid or semiarid regions.

Correction of the properties of compost-based potting media, such as lowering their $\mathrm{pH}$, incorporation of slow-release $\mathrm{N}$ and/or $\mathrm{P}$ fertilizers, and mixing with peat would probably improve their performance. Taking into account that the market price of peat-based potting media is almost twice that of compost-based media, it would be a feasible choice.

\section{Acknowledgements}

This work was supported by the Agencia de Medio Ambiente of the Junta de Andalucía and by Fertilizantes Orgánicos Melguizo SL.

\section{$\underline{\text { 6. References }}$}

Ansorena J., 1994. Sustratos. Propiedades y Caracterización. Mundi Prensa. Madrid. Spain. $172 \mathrm{p}$

Bunt A.C., 1983. Physical properties of mixtures of peats and minerals of different particle size and bulk density for potting substrates. Acta Horticulturae 150: 143153 
Chen Y., Y. Inbar \& Y. Hadar, 1988. Composted agricultural wastes as potting media for ornamental plants. Soil Science 145 (4): 298-303

de Boodt M. \& O. Verdonck, 1972. The physical properties of the substrates used in horticulture. Acta. Hortic. 26: 37-44

Gillman G.P., 1979. A proposed method for the measurement of exchange properties of highly weathered soils. Austr. J. Soil Res. 17: 129-139

Inbar Y., Y. Hadar \& Y. Chen, 1993. Waste Management. Recycling of Cattle Manure: The Composting Process and Characterization of Maturity. J. Environ. Qual. 22: 857-863

Lindsay W.L. \& W.A. Norwell, 1978. Development of a DTPA soil test for zinc, iron, manganese and copper. Soil. Sci. Soc. Am. J. 42: 421-428

Madejón, E., M.J. Díaz, R. López, C.J.M. Murillo \& F. Cabrera, 1995. Corn fertilization with three sugarbeet vinasse composts. Fresenius Envir. Bull. 4, 232237

Madejón, E., M.J. Díaz, R. López, C. Lozano \& F. Cabrera, 1996. Cotton fertilization with composts of sugarbeet vinasse and agricultural residues. Fertilizer Research 43: $179-182$

Verdonck, O., de Boodt, M. \& Gabriels, R., 1987. Compost as a growing medium for horticultural plants. In Compost Production, Quality and Use. Elsevier Applied Science. London, 399-405 


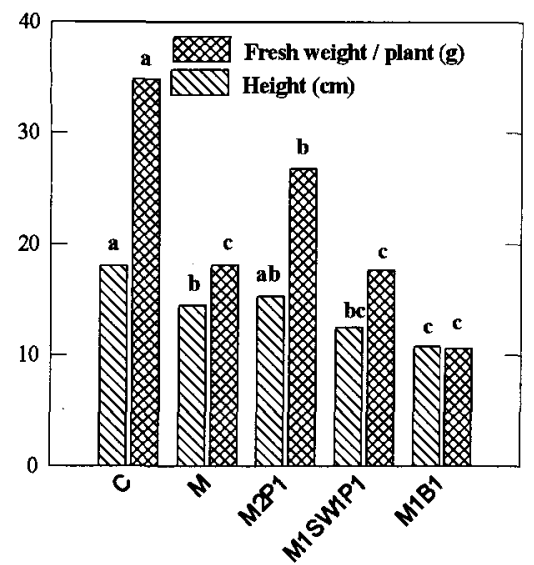

Figure 1. Plant development at 45 days in different potting media

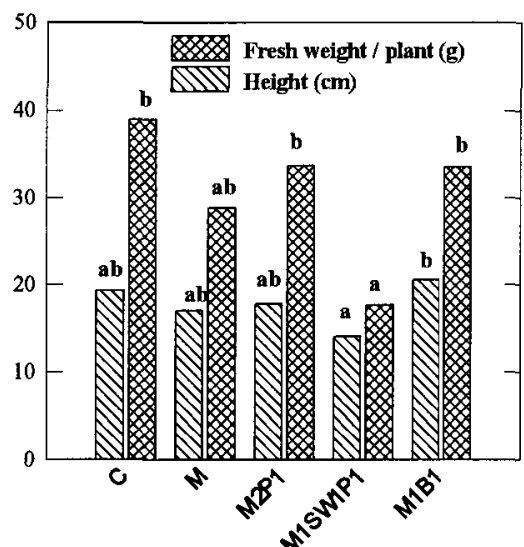

Figure 2. Plant development at $\mathbf{1 0 0}$ days in different potting media

Table 1.- Physical properties of the potting media

\begin{tabular}{llllllll}
\hline & & $\begin{array}{l}\text { Ideal } \\
\text { Substrate }\end{array}$ & $\mathrm{C}$ & $\mathrm{M}$ & M2P1 & M1SW1P1 & M1B1 \\
\hline Ash & $\% \mathrm{w} / \mathrm{w}$ & $<20$ & $13.2 \mathrm{a}$ & $61.8 \mathrm{c}$ & $60.8 \mathrm{c}$ & $54.2 \mathrm{~b}$ & $50.1 \mathrm{~b}$ \\
Particle density & $\mathrm{Mg} \mathrm{m}^{-3}$ & $1.45-2.65$ & $1.64 \mathrm{a}$ & $2.09 \mathrm{c}$ & $2.07 \mathrm{c}$ & $2.00 \mathrm{~b}$ & $1.96 \mathrm{~b}$ \\
Bulk density & $\mathrm{Mg} \mathrm{m}^{-3}$ & $<0.4$ & $0.107 \mathrm{a}$ & $0.284 \mathrm{~d}$ & $0.230 \mathrm{c}$ & $0.179 \mathrm{~b}$ & $0.227 \mathrm{c}$ \\
$\begin{array}{l}\text { Total porosity } \\
\text { Container }\end{array}$ & $\%$ vol & $>85$ & $93.5 \mathrm{~d}$ & $86.4 \mathrm{c}$ & $\mathbf{8 8 . 9 \mathrm { b }}$ & $91.1 \mathrm{a}$ & $88.4 \mathrm{~b}$ \\
$\begin{array}{l}\text { capacity } \\
\text { Air space }\end{array}$ & $55-75$ & $61.8 \mathrm{c}$ & $54.2 \mathrm{~b}$ & $54.6 \mathrm{~b}$ & $50.6 \mathrm{ba}$ & $48.2 \mathrm{a}$ \\
\hline
\end{tabular}


Table 2 - Chemical properties of the potting media

\begin{tabular}{|c|c|c|c|c|c|c|}
\hline & & $\mathrm{C}$ & $\mathrm{M}$ & $\mathrm{M} 2 \mathrm{P} 1$ & M1SW1P1 & M1B1 \\
\hline $\mathrm{pH}(1: 6)$ & & $5.62 a$ & $7.77 \mathrm{c}$ & $7.34 b$ & $7.09 \mathrm{~b}$ & $7.23 \mathrm{~b}$ \\
\hline E.C. $(1: 6)$ & $\mathrm{dS} \mathrm{m}^{-1}$ & $0.43 a$ & $0.46 \mathrm{a}$ & $0.41 \mathrm{a}$ & $0.44 a$ & $0.35 a$ \\
\hline $\mathrm{C} / \mathrm{N}$ & & $50 \mathrm{c}$ & $10 \mathrm{a}$ & $11 \mathrm{a}$ & $17 \mathrm{ab}$ & $22 \mathrm{~b}$ \\
\hline CEC & $\mathrm{cmol} \mathrm{l}^{-1}$ & $109 a$ & $295 \mathrm{c}$ & $239 b$ & $192 b$ & $238 b$ \\
\hline Exchangeable- $\mathrm{Ca}$ & $\mathrm{cmol} \mathrm{l}^{-1}$ & $108 \mathrm{a}$ & $176 \mathrm{c}$ & $147 \mathrm{~b}$ & $111 \mathrm{a}$ & $141 b$ \\
\hline Exchangeable-Mg & $\mathrm{cmol} \mathrm{l}^{-1}$ & $7.4 \mathrm{a}$ & $57.9 \mathrm{~d}$ & $46.7 \mathrm{c}$ & $27.6 \mathrm{~b}$ & $32.9 \mathrm{~b}$ \\
\hline Exchangeable-Na & $\mathrm{cmol} \mathrm{l}^{-1}$ & $0.96 a$ & $3.35 \mathrm{c}$ & $2.62 b$ & $4.48 \mathrm{~d}$ & $3.63 \mathrm{c}$ \\
\hline Exchangeable-K & $\mathrm{cmol} \mathrm{l}^{-1}$ & $2.3 \mathrm{a}$ & $17.3 \mathrm{~d}$ & $11.5 \mathrm{c}$ & $7.3 b$ & $8.4 b$ \\
\hline $\mathrm{N}$ & $\% \mathrm{w} / \mathrm{w}$ & $0.88 \mathrm{a}$ & $1.91 \mathrm{e}$ & $1.75 \mathrm{~d}$ & $1.38 \mathrm{c}$ & $1.16 \mathrm{~b}$ \\
\hline $\mathrm{P}$ & $\% w / w$ & $0.07 \mathrm{a}$ & $0.33 c$ & $0.28 \mathrm{c}$ & $0.30 \mathrm{c}$ & $0.21 b$ \\
\hline K & $\% \mathrm{w} / \mathrm{w}$ & $0.08 \mathrm{a}$ & $0.32 \mathrm{~b}$ & $0.27 \mathrm{~b}$ & $0.25 \mathrm{~b}$ & $0.23 b$ \\
\hline $\mathrm{Ca}$ & $\% \mathrm{w} / \mathrm{w}$ & $2.50 \mathrm{a}$ & $7.57 \mathrm{~d}$ & $6.83 c$ & $5.44 b$ & $5.11 \mathrm{~b}$ \\
\hline $\mathrm{Mg}$ & $\% \mathrm{w} / \mathrm{w}$ & $0.09 a$ & $0.79 \mathrm{~d}$ & $0.73 d$ & $0.54 \mathrm{c}$ & $0.28 \mathrm{~b}$ \\
\hline $\mathrm{Na}$ & $\% \mathrm{w} / \mathrm{w}$ & $0.08 \mathrm{ab}$ & $0.09 \mathrm{ab}$ & $0.05 a$ & $0.13 b$ & $0.09 a b$ \\
\hline $\mathrm{Cu}$ & $\mathrm{mg} \mathrm{kg}^{-1}$ & $13 a$ & $23 b$ & $23 b$ & $67 c$ & $17 \mathrm{~b}$ \\
\hline Mn & $\mathrm{mg} \mathrm{kg}{ }^{-1}$ & $69 a$ & $286 d$ & $253 \mathrm{c}$ & $213 b$ & $186 \mathrm{~b}$ \\
\hline $\mathrm{Zn}$ & $\mathrm{mg} \mathrm{kg}^{-1}$ & $45 a$ & $72 b$ & $66 \mathrm{~b}$ & $167 \mathrm{c}$ & $52 a$ \\
\hline DTPA-Fe & $\mathrm{mg} \mathrm{l}^{-1}$ & $5.2 \mathrm{a}$ & $80 d$ & $56 \mathrm{c}$ & $63 c$ & $20 \mathrm{~b}$ \\
\hline DTPA-Cu & $m g ~^{-1}$ & $0.14 a$ & $2.24 \mathrm{~d}$ & $1.61 \mathrm{c}$ & $7.64 \mathrm{e}$ & $1.27 \mathrm{~b}$ \\
\hline DTPA-Mn & $\mathrm{mg} \mathrm{l}^{-1}$ & $1.4 \mathrm{a}$ & $30.1 \mathrm{c}$ & $23.2 \mathrm{~b}$ & $20.8 b$ & $33.4 \mathrm{c}$ \\
\hline DTPA-Zn & $\mathrm{mg} 1^{-1}$ & $1.3 \mathrm{a}$ & $12.3 \mathrm{c}$ & $8.7 \mathrm{~b}$ & $23.1 \mathrm{~d}$ & $8.0 \mathrm{~b}$ \\
\hline
\end{tabular}

Table 3 - Leaf nutrient contents in geranium

\begin{tabular}{|c|c|c|c|c|c|c|}
\hline & & $\mathrm{C}$ & M & M2P1 & M1SW1P1 & M1B1 \\
\hline \multicolumn{7}{|c|}{45 days } \\
\hline $\mathbf{N}$ & $\%$ & 2.87 & 3.25 & 3.41 & 3.28 & 2.38 \\
\hline $\mathrm{P}$ & $\%$ & 0.26 & 0.17 & 0.21 & 0.15 & 0.27 \\
\hline K & $\%$ & 2.66 & 4.24 & 4.21 & 4.26 & 4.34 \\
\hline \multicolumn{7}{|c|}{100 days } \\
\hline $\mathrm{N}$ & $\%$ & $4.41 \mathrm{a}$ & $3.91 \mathrm{a}$ & $4.02 \mathrm{a}$ & $4.33 \mathrm{a}$ & $4.11 \mathrm{a}$ \\
\hline $\mathrm{P}$ & $\%$ & $0.27 \mathrm{a}$ & $0.30 \mathrm{a}$ & $0.30 \mathrm{a}$ & $0.30 \mathrm{a}$ & $0.33 \mathrm{a}$ \\
\hline $\mathrm{K}$ & $\%$ & $1.83 \mathrm{a}$ & $3.87 \mathrm{~b}$ & $3.53 \mathrm{~b}$ & $4.30 \mathrm{~b}$ & $4.17 \mathrm{~b}$ \\
\hline $\mathrm{Ca}$ & $\%$ & $2.52 \mathrm{~b}$ & $1.64 \mathrm{a}$ & $1.52 \mathrm{a}$ & $1.74 \mathrm{a}$ & $1.74 \mathrm{a}$ \\
\hline $\mathrm{Mg}$ & $\%$ & $0.35 \mathrm{a}$ & $0.46 a$ & $0.42 \mathrm{a}$ & $0.37 \mathrm{a}$ & $0.42 \mathrm{a}$ \\
\hline $\mathrm{Na}$ & $\%$ & $0.61 \mathrm{c}$ & $0.10 \mathrm{a}$ & $0.17 \mathrm{ab}$ & $0.30 \mathrm{~b}$ & $0.13 \mathrm{ab}$ \\
\hline $\mathrm{Fe}$ & $\mathrm{mg} \mathrm{kg}^{-1}$ & 271. c & $288 \mathrm{c}$ & $219 b c$ & $112 a b$ & $87 \mathrm{a}$ \\
\hline $\mathrm{Mn}$ & $\mathrm{mg} \mathrm{kg}$ & $177 \mathrm{~b}$ & $31 \mathrm{a}$ & $29 \mathrm{a}$ & $45 \mathrm{a}$ & 46. a \\
\hline $\mathrm{Zn}$ & $\mathrm{mg} \mathrm{kg}^{-1}$ & $57 \mathrm{a}$ & $41 \mathrm{a}$ & $48 \mathrm{a}$ & $60 \mathrm{a}$ & $51 \mathrm{a}$ \\
\hline
\end{tabular}

